ADLFI. Archéologie de la France -

une revue Gallia

Rhône-Alpes | non-daté

\title{
Ombilic des Basses-Terres
}

\section{Stéphane Bleu}

\section{OpenEdition \\ Journals}

Édition électronique

URL : http://journals.openedition.org/adlfi/6984

ISSN : 2114-0502

Éditeur

Ministère de la culture

Référence électronique

Stéphane Bleu, «Ombilic des Basses-Terres », ADLFI. Archéologie de la France - Informations [En ligne], Rhône-Alpes, mis en ligne le 01 mars 2007, consulté le 03 mai 2019. URL : http://

journals.openedition.org/adlfi/6984

Ce document a été généré automatiquement le 3 mai 2019.

(c) Ministère de la Culture et de la Communication, CNRS 


\title{
Ombilic des Basses-Terres
}

\author{
Stéphane Bleu
}

Identifiant de l'opération archéologique : 229458

Date de l'opération : 2006 - 2007 (PR)

1 Dans le cadre du PCR dirigé par J.-F. Berger «Milieu et peuplement en plaine du BasDauphiné de la naissance de l'agriculture jusqu'à nos jours", suite à la première triennale, un certain nombre de résultats ont été obtenus et un bilan critique des dernières années a été développé. En effet, même si les résultats sont engageants et les enseignements novateurs (méthodes, occupation du sol, topographie de l'agglomération, paléoenvironnement, accessibilité de la documentation, gestion du site), il convient d'être conscient des limites ou de certaines insuffisances des démarches.

\section{Les prospections et les études géophysiques}

2 Des prospections systématiques avec relevés du mobilier au GPS différentiel ont été menées en collaboration avec V.Vachon (INRAP), sur un site à haut potentiel archéologique, cœur supposé de l'agglomération secondaire d'Aoste (voir plateau des Côtes, Saint-Pierre, La Planche).

Une prospection magnétique a été réalisée sur les parcelles jouxtant l'officine de potier de Normandoz à Aoste (Isère), par l'entreprise Terra Nova. Elles ont permis de localiser un ou deux nouveaux fours. Dans la parcelle sud, deux fossés parallèles ont été clairement identifiés indiquant la présence de l'ancienne voie romaine reliant Aoste (Isère) à Vienne (Isère). D'autres structures ont également été identifiées, mais feront l'objet d'une analyse plus fine. 


\section{Les survols aériens}

4 Le traitement de la documentation recueillie au cours des survols de l'année 2006 est toujours en cours. Le dépouillement des clichés est laborieux, car une foule de formes paléofluviales et hydrologiques apparaissent et doivent être vérifiées systématiquement. En ce qui concerne les sites archéologiques, le dépouillement des clichés à la lumière des résultats des prospections permet de confirmer la présence de quelques sites. Ainsi, au niveau du site Morel 6/7, plusieurs structures (voie et ses fossés, petit batiment quadrangulaire) sont maintenant parfaitement identifiées au nord-est du bâtiment sondé en 2003. D'après le mobilier archéologique découvert sur le site l'occupation semble dater de l'Antiquité tardive (Drag. 45 à décor de tête de lion) et de l'époque mérovingienne. Les prospections réalisées sur place en 2002 avaient livré des fragments d'adobe (?) brûlés. Il pourrait s'agir d'un petit fanum.

\section{Prospections}

5 Une carrière de meule a été repérée en prospection sur la commune de Saint-Victor-deMorestel en 2006 (A. Vaudray, S. Bleu et S. Perrin). Il s'agit probablement d'une carrière fournissant les nombreux moulins à huile et à farine sur la Bièvre et l'Huert.

6 Suite à une information orale de M.-G. Burfin (hameau du Sablonnet), une prospection a été réalisée avec M. Morel au quartier des Nappes, dans un petit bois, sur les vestiges d'un ancien moulin. Le bâtiment en ruine et la machinerie avec la meule encore en place ont été observés. À proximité de cette ruine, se trouvait une pierre tombale d'époque contemporaine qui a été nettoyée rapidement mais dont le relevé sera réalisé dans les années futures. Peut-être s'agit-il de la tombe du meunier (?). Cette découverte devrait permettre de replacer ce moulin dans un système plus cohérent des moulins dans la plaine des Basses-Terres et de leur évolution historique technique. Une comparaison sera réalisée avec les contraintes liées à l'utilisation des biefs et des canaux dans un marais ou une zone humide.

7 Monsieur E. Guinet (demeurant à Aoste) nous a informé de la découverte fortuite, dans le courant de l'année 2007, d'un important autel de pierre calcaire d'environ $2 \mathrm{~m}$ de hauteur, au lieu-dit Fontagnieu où avaient été identifiés plusieurs sites au cours de la campagne de prospections des années 1997-1998. Le monument découvert lors de travaux ruraux en contrebas d'une butte dans le courant de l'année 2007 (mois de mai ?), se trouve aujourd'hui dans la cour de la ferme. Il s'agit d'un autel de calcaire (hauteur totale : 2,38 m ; hauteur du dé : 1,6 m). D'après les inventeurs, au centre du cube se développe une inscription en caractère romain, qu'il n'a pas été possible d'observer jusqu'à présent.

8 BLEU Stéphane 
INDEX

operation Prospection (PR)

Index chronologique : Antiquité tardive, ép. contemporaine, ép. mérovingienne, Moyen Âge*, haut Moyen Âge, VIe siècle apr. J.-C., VIIe siècle apr. J.-C.

Index géographique : Rhône-Alpes, Isère (38), Granieu, Brangues, Aoste, Corbelin, Avenières, Veyrins-Thuellin, Vézeronce-Curtin, Bouchage

\section{AUTEURS}

STÉPHANE BLEU

INRAP 